\title{
Nominations open for 10th BMJ Awards
}

\author{
Anne Gulland
}

\section{London}

Doctors are urged to enter for the most prestigious honours in UK medicine.

Nominations opened on 28 October for The BMJ Awards, now in their 10th year of celebrating outstanding achievement in medicine. Doctors have until Friday 26 January to put themselves-or colleagues-forward in 14 categories across a range of specialties.

The award winners will be announced at a glittering ceremony on Thursday 10 May after a rigorous judging process.

Fiona Godlee, BMJ editor in chief, said that she was proud to be celebrating medical excellence in the 10 year anniversary of the awards.

"When times are tough in the NHS it is incumbent on us to recognise all the hard work going on in our health service. The awards showcase innovation and creativity, encourage learning, and allow us to celebrate some truly amazing teamwork and achievement," she said.

The award categories are:

Anaesthesia and perioperative medicine team-sponsored by the Royal College of Anaesthetists

\author{
Diagnostic team—-sponsored by Alliance Medical \\ Primary care team—sponsored by MDDUS \\ Clinical leadership team \\ Outstanding contribution to health \\ Dermatology \\ Palliative and hospice-sponsored by Hospice UK \\ Education team of the year \\ Cancer care \\ Innovation team of the year \\ Mental health \\ Patient partnership \\ UK research paper 2018 \\ Emergency team
}

To apply and for more information go to www.thebmjawards/bmj.com

Published by the BMJ Publishing Group Limited. For permission to use (where not already granted under a licence) please go to http://group.bmj.com/group/rights-licensing/ permissions 